\title{
Explanation in Historiography
}

Link to publication record in Manchester Research Explorer

\section{Citation for published version (APA):}

Macdonald, C., Macdonald, G., \& Tucker, A. (Ed.) (2008). Explanation in Historiography. In A Companion to the Philosophy of History and Historiography (pp. 342-352). John Wiley \& Sons Ltd.

\section{Published in:}

A Companion to the Philosophy of History and Historiography

\section{Citing this paper}

Please note that where the full-text provided on Manchester Research Explorer is the Author Accepted Manuscript or Proof version this may differ from the final Published version. If citing, it is advised that you check and use the publisher's definitive version.

\section{General rights}

Copyright and moral rights for the publications made accessible in the Research Explorer are retained by the authors and/or other copyright owners and it is a condition of accessing publications that users recognise and abide by the legal requirements associated with these rights.

\section{Takedown policy}

If you believe that this document breaches copyright please refer to the University of Manchester's Takedown Procedures [http://man.ac.uk/04Y6Bo] or contact uml.scholarlycommunications@manchester.ac.uk providing relevant details, so we can investigate your claim.

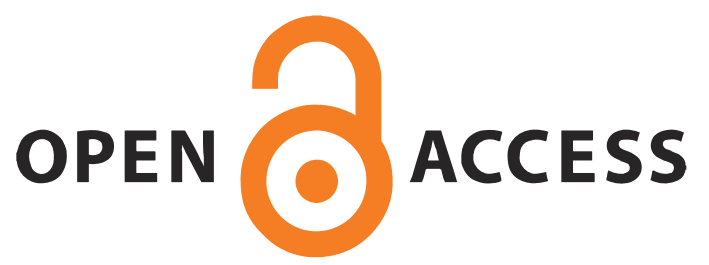




\title{
Explanation in Historiography
}

\author{
GRAHAM MACDONALD AND CYNTHIA MACDONALD
}

Explanations may have some essential common core, or the notion of explanation may resemble what Wittgenstein called a "family-resemblance" concept, whose members need not share the same set of features, but may be more loosely connected by various similarities. One can also attend to different philosophical aspects of explanations, such as their logical structure, their epistemic import, or their pragmatic virtues. These aspects may apply to particular putative explanations in various contexts; for example, causal explanations in mechanics, teleological explanations in biology, or intentional explanations of actions.

Explanation in historiography concerns past events. Events come in smaller and larger clumps; the killing of a soldier may be part of a battle within a war, defeat in which causes a decline in the fortunes of an empire. Other events, large and small, will also be contributory factors to the decline; for example, the failure of the harvest due to the drought will affect the economy and so render the empire more vulnerable to attack.

Different historians will be interested in different aspects of this large-scale event, so it would be unsurprising if their explanations of the facets they find fascinating did not yield explanations with differing styles and structures. Historically, the main cleavage has been between subjective understanding of the meaning of the action from an agent's perspective and the objective explanation of the action (Wright 1971: Martin 1977: ch. 5).

The underdetermination of historiographic facts by the evidence is another reason for different types of explanation: Fernand Braudel (1981: 47-51), for example, had to exert some considerable effort to establish the pattern of population growth in the world during 1500-1800. Having satisfied himself that there is a general pattern of growth in the eighteenth century, he searched for an explanation. Was it caused, perhaps, by technological advances, particularly in agriculture and health care, these in turn producing a decline in mortality rates? But the phenomenon of demographic change was too general; it included territories where there was no significant technological advance. Perhaps, then, it was caused by more space being available through a process of "inward colonization," whereby previously unused territory within a country was becoming increasingly inhabited. But this looks more like effect than cause, the population growth causing the territorial expansion, and not the reverse. Braudel eventually settles on one important factor: climate change. This explanation is fleshed 


\section{GRAHAM MACDONALD AND CYNTHIA MACDONALD}

out by connecting climate and harvests and then noting the importance of harvests for a mainly peasant population: "The rhythm, quality and deficiency of harvests ordered all material life" (Braudel 1981: 49).

This type of explanation of a large-scale historical event does not, at least not immediately, raise particular philosophic problems relating to historiographic explanation. The explanation is straightforwardly causal. The hypothesis that variations in the climate produced the fluctuation in population is testable by looking for significant correlations between the two variables; our understanding of the effect is further increased by noting the causal connection between the quality and quantity of a harvest and the climactic conditions under which the harvest was grown. This is an example of what we may call "macro-historical explanation," and it resembles a pattern of explanation that some philosophers of science and scientists would find familiar, explanation via the subsumption of particular events under causal laws. Arguably, though the causal laws doing the work in the above explanation cannot be formulated with the precision, nor tested with the rigour, of those found in physics and chemistry, it would be niggardly to refuse them explanatory status on that account. They are ceteris paribus laws, familiar enough from other contexts such as biology, ecology, economics, and so on.

This model of explanation has been articulated and defended most notably by Hempel and Oppenheim (1953), then applied to explanation in historiography in a number of papers by Hempel (1965). This analysis of explanation initially provided a two-fold classification of scientific explanations. An explanation is legitimate qua explanation if and only if it provides the means to deductively derive a description of the event being explained (the explanandum) from a statement of a law and a description of some initial conditions, or if the law-statement and description of initial conditions makes the explanandum highly probable. This account clearly makes the presence of a law essential to all scientific explanation and has been dubbed the "nomological" or "covering law" model of explanation.

Amendments to this model might make its application to historiography less controversial, allowing for elliptical explanations, partial explanations, and explanation sketches. An elliptical explanation does not make explicit mention of the laws presumed in the explanation or does so allusively, more or less vaguely. In the example given above, Braudel does not explicitly state any laws connecting climactic conditions to harvest-quality; he simply assumes common knowledge that the causally relevant climactic factors impact on the quantity and quality of certain harvests. For Hempel, though, such a "thin" explanation requires filling out if it is to be a full-fledged explanation. As it stands, he claims, the explanation is "elliptically formulated," omitting "certain laws or particular facts which it tacitly takes for granted, and whose explicit citation would yield a complete deductive-nomological argument” (Hempel 2001a: 282). It is here that the historian might demur, claiming that the explanation is fully satisfactory as it stands.

An elliptical explanation, on Hempel's account, is elliptical because the explanans requires "completion"; a partial explanation is partial because the explanandum is derivable form the explanans only if it is described in terms more general than those initially given. This style of explanation works by explaining the occurrence of an action of generic type $P$ where the target action is of a more specific type $Q$. For 
example, explaining the French Revolution as a case of revolutions in general. An explanation sketch is neither specific enough, nor complete enough, to qualify as either partial or elliptical. Such an explanation "may suggest, perhaps quite vividly and persuasively, the general outlines of what, it is hoped, can eventually be supplemented so as to yield a more closely reasoned argument based on explanatory hypotheses which are indicated more fully, and which more readily permit of critical appraisal by reference to empirical evidence" (Hempel 2001a: 284).

Many issues arise from the above typology of explanations. First, in the discussion of partial explanation it is clear that the partiality of an explanation is a function of the description of the event or action being explained. In the example given, if one were to ask: "Why did a revolution happen in France?" then the explanation given would not be partial. It is only because the event has been given a more precise specification that one sees the explanation as being partial. The classification of explanations as partial is context dependent and conceptually laden.

Second, Hempel admits that even an explanation sketch can be persuasive. This would lead us to inquire into the psychological, some would say pragmatic, features of explanations. If an explanation, even though it fails to meet the criteria of ideal explanation as adumbrated above, leads to enhanced understanding, and those seeking understanding are epistemically content, why does it not qualify as a fully satisfactory explanation? Would it add anything to our understanding to be given a precise law-like formulation of the link between certain climates and crop growths? And does it detract from the explanation that it doesn't explain the exact percentage of population growth during the relevant period? What is at issue here is whether a causal explanation can be complete in the absence of a law relating the cause(s) to the effect. Pragmatic accounts (e.g. van Fraassen 1980; Achinstein 1983; Smart 1990; Tucker 2004) answer negatively and develop models of explanation that do not include laws as necessary components, most notably by separating issues concerning the structure of explanation from issues relating to its justification and validity.

The standard objection leveled at Hempel is that he has unjustifiably extrapolated from a highly idealized explication of explanation in one setting, of Newtonian physics, and made this the normative requirement on all explanation. This, however, overlooks the flexibility of Hempel's analysis of explanation. Consider "functional explanation" that explains the existence of a feature or activity by citing the effects it brings about. Functional explanations may be:

1 Purposive: Increasing scale yields economies; managers are aware of that so, desiring economies, increased scale results.

2 Darwinian: In a competitive environment, increase in scale both yields economies and helps survival. Managers don't know this, but scale (of some firms) is increased "by chance." Survival of only those firms with this chance variation produces increase in scale of production.

3 Lamarckian: Species adapt to their environment; an organ not fully adapted becomes fully adapted via a struggle to use it in its environment. 


\section{GRAHAM MACDONALD AND CYNTHIA MACDONALD}

4 Self-deception: Here the functional fact operates through the minds of agents without the agents' full awareness.

Take the supposed fact of the ever-increasing productive power of technology. One explanation is straightforwardly causal: knowledge grows, and one aspect of that growth (technical knowhow) effects a transformation in the way a society produces goods. Alternatively, some Marxist historians reversed the order of explanation: they cite changes in the nature of productive forces in explaining social change. The institutions that provide the new knowledge (schools, universities, research departments), and the social patterns allowing for the re-organization of labor, are the way they are or exist with the features they have because they facilitate enhanced productive power. They have the function of facilitating the optimal use of the available technology, and of adjusting to improved technologies when they become available.

G. A. Cohen invites us to consider the difference between:

(a) Event $f$ brought about event $e$.

(b) Event $f$ preceded event $e$.

(a), he claims, ventures a causal explanation of $e$, and (b), though explanatory in some circumstances is not explanatory in all. It is only in virtue of a true generalization (what Hempel would call a "covering law") that both are explanatory.

Likewise, consider:

(c) The function of $x$ is to $\varnothing$.

(d) The beneficial effect of $x$ is to $\varnothing$.

Again, (c) ventures a functional explanation, and (d) though explanatory in some circumstances, is not explanatory in all. What makes (c) and (d) explanatory (when they are) is a true generalization of a special form, a consequence law, which is "a universal conditional statement whose antecedent is a hypothetical causal statement" (Cohen 1979: 259). For example, if it were the case that, if an event of type $E$ were to occur at $t$, then it would bring about an event of type $\mathrm{F}$ at $t_{2}$, then an event of type $\mathrm{E}$ occurs at $\mathrm{t}_{3}$.

Roughly, the idea is that E's disposition to cause tokens of $\mathrm{F}$ explains the occurrence of a token of $\mathrm{E}$. e.g. if $\mathrm{E}=$ performance of rain dance of type $\mathrm{R}$; $\mathrm{F}=$ rise in social cohesion, then the law says:

Whenever performance of rain dance $\mathrm{R}$ would bring about, shortly thereafter, a rise in social cohesion, rain dance $\mathrm{R}$ is performed.

The rain dance (its performance) is not explained by the rise in social cohesion (causes cannot post-date their effects); the performance of the rain dance is explained by this dispositional fact.

We are not suggesting that historians must use functional explanation (or explanation by "consequence laws"), though those historians who are interested in the explanation of changing patterns in cultural evolution should be aware of this style of 
explanation (see some of the papers in Boyd and Richerson 2005, for interesting material on cultural evolution). Lewens (2007: 50-5; cf. Gat 2007) suggests that all evolutionary explanations that rely on processes of selection employ the type of consequence law discussed by Cohen. Functional explanation accords with the Hempelian model: it is because there are consequence laws that "consequence style" explanation is genuine, even though "we may have a good reason for thinking that a functional explanation is true even when we are at a loss to conjecture by what means or mechanism the functional fact achieves an explanatory role" (Cohen 1978: 266).

Functional explanations (using consequence laws) are partial explanations because they underdetermine the explanandum: alternatives to the rain dance may produce the same result (social cohesion). It may be that in these conditions, given the history of the tribe etc., only a rain dance will be functional in the required way. Otherwise one may retreat to the less specific: if an (unspecified) ceremonial will reinforce group identity, then some such ceremonial will be performed. No explanation explains all the properties of the explanandum. So, the performance of a ritual may be functionally explained, even though which ritual it is may not be. Whether the explanations using this consequence-law style are otherwise satisfactory is another question.

The Hempel-Oppenheim model, suitably modified to deal with some of the objections raised within the philosophy of science literature (see Godfrey-Smith 2003: ch. 13, for a discussion of these objections) may adequately cover macro-historical explanations, despite the unpopularity of this model in the philosophy of historiography for the last few decades. This does not mean that we think that there is a set of necessary and sufficient conditions whose satisfaction would ensure the explanatory status of any set of sentences; there may always be the potential for counter-examples to the analysis. The history of attempts to provide just such a set of necessary and sufficient conditions on knowledge claims support the thought that any "analysis" of explanation will itself be partial.

Another form of historiographic inquiry, associated with the "explanation" (often termed "interpretation") of the kind of macro-historical events we have been considering is classification. Was the English Revolution really a revolution? Often that is a matter of debating the correct interpretation of what has occurred, this being conducted alongside increasingly detailed research into the "entrails" of the appropriate period. Sometimes this interpretative process has been construed as essentially synthetic, the integrating into a satisfying whole otherwise disconnected features of the era. Subsumption under a concept, colligation (see ch. 12 on colligation, this volume), may be illuminating in the way an explanation ought to be.

Even if the above remarks in defence of generalism are true, there remains a question of the purport of the putative explanations. Consider another example, that of the severe consequences of the potato famine in Ireland during 1846-51 (English 2006). The population of Ireland decreased from an estimated 8.3 million in the early $1840 \mathrm{~s}$ to around 6.4 million in 1851, with about a million emigrating and the rest dying of famine-related diseases. How could the failure of a single crop lead to such devastation? The explanation, unsurprisingly, is multi-factorial: relevant features of the situation were the structure of agriculture, the dependence of the peasantry on a diet of potatoes, the lack of political power of those most affected, the length of the famine, 


\section{GRAHAM MACDONALD AND CYNTHIA MACDONALD}

the failure of the peasantry to include a potential source of food (fish) in their diet, and insufficient help provided by the central (English) government agencies.

It may well be true that there are laws of some sort underwriting the connections between these various factors and the devastation wrought by the protracted famine, but the person seeking an understanding of what happened may not be in the business of trying to assess any such law-like connections. The purpose of this historical inquiry is to shed some light on a particular set of events, the presumption being that the relevant factors would be causally influential in the bringing about of those events. We are not claiming like Graham (1983: 46-51), Elliott Sober, Carol Cleland (ch. 4, this volume), and Tucker (2004) that the interest of historians in explaining events is different from that of theoretical scientists in being directed to the particular token as opposed to the type. Our claim is rather just that this is a legitimate form of historiographic explanation. It is, we contend, the notion of cause that is doing the explanatory work here, not the (background) presence of laws. Knowing the causes implicated in some historical event or process allows us to satisfy what Hempel calls a "necessary condition of adequacy for explanations," which is that any explanation of $\mathrm{X}$ must supply information providing good grounds for believing that X did in fact occur (Hempel 2001b: 299). Lipton (2004) also requires of any explanation that it provide grounds for believing the explanandum occurred. This epistemological requirement will be satisfied if there is a non-contingent connection between causes and their effects. On some Humean conceptions of the causal relation, this non-contingency is secured by the existence of a law "underwriting" the putative relation, and it is, we believe, this conception of causality that induced Hempel to embrace the covering law model of explanation. This leads us to discuss the use of singular causal explanation in the explanation of micro-historical events, particularly the actions of historical agents.

\section{2}

Historiographic explanation of particular events has sometimes been categorized as narrative explanation. Such explanations are said to set events in a context and to place them within a series of events which can be seen to have a connecting thread. It is the connecting thread that supplies the explanatory illumination: it is because of the relevance of the connections that one sees the explained event as being the plausible (or even inevitable) outcome of what has gone before. The event has been "made sense of," and so rendered unsurprising, when such a narrative account is provided. (Alternatively, W. B. Gallie (1964) found emphasis on contingency and unpredictability essential to narrative understanding, but we think that explanation must reduce (but not necessarily eliminate) contingency.)

The challenge to the particularist narrativist is to say more about the connecting thread between explanans and explanandum without recourse to law-like generality. Historiographic narration is sometimes explicated along the lines of supplying the plot to a story, the plot being said to collect together the otherwise unrelated events into an intelligible whole (see White 1973, for a typology of "plots"); or it is rendered, more 
controversially, along the lines of an overarching intention which supplies the meaning linking the subsumed events. The difficulty is in being more non-metaphorically explicit about how "plot" or intention can illuminate historical deeds, as distinct of historiographic texts, in such a way as to make certain outcomes follow "by necessity or probability" (Aristotle, quoted in Velleman 2003: 1). In what follows we suggest ways in which we think this can be done, concentrating on issues relating to explanation while ignoring complications due to the dubious applicability of notions such as "plot" and "story" to historical events, as distinct from their depictions in historiography. We concentrate on the explanations of the actions of historical agents as we think that it is to actions that narrative explanation is most usefully applied. The "making sense" that narrative supplies is seen most plainly in an explanation of a series of events that consist of actions performed in pursuit of a goal; we see why some action was performed when we know the motivational and cognitive states of the agent, and the context (social and physical) within which she was acting. These psychological states may be exceedingly complex, consisting of a number of conscious, sub-conscious (sub-doxastic), and unconscious cognitive and non-cognitive factors. Nevertheless, when we have the requisite information concerning the agent's psychological profile we can see an action as being necessitated by those psychological states, and so are in a position to explain that resulting action.

Reports of significant events are vastly complicated, so explanations attributing only psychological states to historical actors will not be sufficient to account for the way those events turned out. The eventual demise of Napoleon had many causes: the decrease in France's population, the effect of disease coupled with logistical problems of food supply during the Russian excursion, the ability of England to escape the worst of an economic blockade, the necessity for Russia to trade with England, the obstinacy of his "defeated" enemies together with the overcoming of their mutual distrust of one another, and so on. Nevertheless, one relevant factor is Napoleon's insatiable appetite for glory, which led him to overstep the bounds of what was militarily and politically feasible (Blanning 2007: 669). This psychological defect explains the initiation of actions that had disastrous consequences.

One task of the historian is to find and supply such psychological information in as plausible a manner as possible, one that takes into account differences in values, upbringing, and social environment between different times and places. Although these differences make the explanatory task that much harder, the resultant explanation is not different in kind from that employed in "ordinary" accounts of why agents act in the way they do. The question of whether these accounts rely essentially on generalist premises has been much disputed, so we now turn to evaluate that controversy.

In a well-known passage Collingwood says: "For history, the object to be discovered is not the mere event, but the thought expressed in it. To discover that thought is already to understand it. After the historian has ascertained the facts, there is no further process of inquiring into their causes. When he knows what happened, he already knows why it happened" (Collingwood 1956: 214).

Collingwood here gives expression to the view that once one has discerned the thought in the action one has no need to inquire further into the causes of that action. One could put the idea this way: the thought in the action both individuates and 


\section{GRAHAM MACDONALD AND CYNTHIA MACDONALD}

illuminates, providing an understanding of the action that makes further (causal) explanation at least redundant. In Collingwood's case this idea is accompanied by a distrust of the use of laws in historiographic explanation; he thought that there was not enough uniformity in the psychologies of historical agents to justify any appeal to general truths about "human nature" in the explanation of actions. But this contingent fact (of historical psychological heterogeneity) is not the main reason for Collingwood's rejection of any appeal to law-based explanation; he was convinced that the logic of action-explanation was different from that of the explanation of (merely) natural events. (For a sensitive discussion of Collingwood's philosophy of historiography see Martin 1977.)

One way of interpreting Collingwood's distinction between the explanation of natural events and that of actions is to deny what has hitherto been presumed, that actions have causes. If this claim is true it would clearly render causal explanation inadmissible - and at the same time remove one argument supporting the essential appeal to laws in historiographic explanation. This argument has its basis in the influential model of causation first proposed by David Hume, that where there are true causal statements linking cause and effect, there is a law "covering" those events, relating them as cause and effect. As Hume put it,

There must be a constant union betwixt the cause and effect. 'Tis chiefly this quality, that constitutes the relation. (Hume 1978: 173)

There are two theses of varying strengths that one can associate with the above. The stronger is that causation is nothing but "constant union," the weaker is that causation requires such constancy to be present. We find the stronger thesis implausible, and so view what constancy there is as being explained by the presence of causation, rather than vice versa. As it happens, the case we are going to present for non-law based historiographic explanation compels us to reject the stronger version of the Humean model, so those committed to it will find our argument wanting. The choice they face is either to accept the generalist account of historiographic explanation or to deny that it works by citing causes.

A related Humean proviso on causally related events is that they be "distinct existences." That is, the events have to be logically independent of each other, and the law governing them must be an "empirical" law, which requires that the antecedent and consequent of the law be conceptually independent. It is this requirement that has produced disquiet amongst those wishing to deny that actions have causes: the putative causes (the intentional states of the agent) do not seem to have the required independence. In order to explain actions, the supposed mental causes are required to make it intelligible that somebody with that set of mental attitudes would act in that way, and this intelligibility is achieved by making the action a rational outcome of those attitudes. The "rational connection" between the attitudes and the resulting action conceptually connects the two (so the action of eating ice-cream is explained by positing the desire to eat ice-cream), and it is precisely this conceptual connection that has been thought to be inconsistent with both the independence characteristic of causes and their effects and the conceptual independence of the antecedent and consequent of the empirical law. The conclusion drawn is that "reasons are not causes." 
Yet, this conclusion is mistaken, or at least it does not follow from these premises alone. Donald Davidson (Davidson 2001a) points out that the two requirements need to be formulated carefully: events related as cause and effect must be "distinct existences," and must have some descriptions under which they instantiate laws (not that they do under every description). On this understanding, if the attitudes are distinct from the actions, then there could well be descriptions of the two (attitudes and action) that figure in laws, but not by virtue of their reason-giving descriptions. That is, the events of my coming to possess a relevant attitude (a belief, say) and of my acting may well fall under laws, but the descriptions that compose the laws need not be descriptions using the vocabulary of "belief," or of "reason"; there may well be physical descriptions of these events that do figure in laws. If there are such law-apt descriptions employing physical vocabulary, then the events so described can be seen to be independent in the sense required for them to qualify as causally related. So the conceptual connection between reason-giving explanations and what they explain (subsequent actions) is not a ground for denying that the attitudes constituting the (motivating) reason cause the action for which they are a reason.

We take it that there is a good case to be made for regarding reason-giving explanations as citing causes of what they explain, and that this can be reconciled with the Humean requirements on cause-effect relations, those of independence and of subsumption by law. And so we take it that much narrative explanation will cite appropriate causes of the actions taken by historical agents, admitting that some such explanations work by citing facilitating (rather than sufficient) causes, thus showing how an action was possible, though not necessitated (see Dray 2000: 225-7, for a discussion of "how-possible" explanation).

This will only be a victory for the generalist, though, if the reason-giving explanation works by essentially averting to the presumed (empirical) law, and nothing in the above supports this view. Davidson claimed that there are no laws in which mental descriptions figure, so not all explanations citing causes need to be seen as conforming to the Hempelian model. He says:

"The most primitive explanation of an event gives its cause; more elaborate explanations may tell more of the story, or defend the singular causal claim by producing a relevant law or by giving reasons for believing such exists. But it is an error to think no explanation has been given until a law has been produced. Linked with these errors is the idea that singular causal statements necessarily indicate, by the concepts they employ, the concepts that will occur in the entailed law. Suppose a hurricane, which is reported on page 5 of Tuesday's Times, causes a catastrophe, which is reported on page 13 of Wednesday's Tribune. Should we look for a law relating events of these kinds? It is only slightly less ridiculous to look for a law relating hurricanes and catastrophes" (Davidson 2001a: 17; see also Davidson 2001b, for further elaboration).

The upshot is that narrative explanation can be distinctively particular; it can pay due attention to a particular context in all its complexity, and provide satisfactory explanations of actions arising from those contexts without resorting to fanciful or trumped-up laws. It can do this while remaining faithful to the spirit of the generalist position: all explanation must reduce the sheer contingency of what is explained. It does this because the factors cited in narrative explanations are causally related (in various ways) to the events they explain. 
We have argued that historiographic explanation comes in many forms. Sometimes general claims form an essential component, whereas at other times only the particular circumstances and psychological states of the agent(s) need to be mentioned. In the former case the generalizations are likely to be laws only in a "loose" sense, one allowing for the law to be imprecisely formulated and limited in scope. We have suggested that Hempel's fairly broad characterization of those different types of explanation using generality will cover these cases. We have argued in addition that there is room for what has been called narrative explanation, a form of causal explanation that does not make essential use of laws, even if the causal relation requires there to be a law covering that relation. Singular causal explanation works because there is a cause in play, not because there is a law in the background.

\section{Acknowledgment}

Work on this article has been supported by a grant from the Marsden Fund of the Royal Society of New Zealand.

\section{Bibliography}

Achinstein, Peter (1983). The Nature of Explanation (Oxford: Oxford University Press).

Blanning, Tim (2007). The Pursuit of Glory: Europe 1648-1815 (London: Allen Lane).

Boyd, R. and Richerson, P. (2005). The Origin and Evolution of Cultures (Oxford: Oxford University Press).

Braudel, Fernand (1981). Civilization \& Capitalism 15th-18th Century: The Structures of Everyday Life (London: Collins).

Cohen, G. A. (1978). Karl Marx's Theory of History (Oxford: Oxford University Press).

Cohen, G. A. (1982). "Functional Explanation, Consequence Explanation, and Marxism," Inquiry, 25(1), pp. 27-56.

Collingwood, R. G. (1956). The Idea of History (New York: Oxford University Press).

Davidson, Donald (2001a). "Actions, Reasons, and Causes," in Davidson 2001c, pp. 3-20.

Davidson, Donald (2001b). "Mental Events," in Davidson 2001c, pp. 207-24.

Davidson, Donald (2001c). Essays on Actions and Events (Oxford: Oxford University Press).

Dray, W. (1971). "On the Nature and Role of Narrative in Historiography," History and Theory, 10, pp. 153-71.

Dray, W. (2000). "Explanation in History," in J. Fetzer (ed.), Science, Explanation and Rationality: Aspects of the Philosophy of Carl G. Hempel (Oxford: Oxford University Press), pp. 217-42.

English, Richard (2006). Irish Freedom: The History of Nationalism in Ireland (London: Macmillan).

Gallie, W. B. (1964). Philosophy and the Historical Understanding (London: Chatto and Windus). Gat, Azar (2007). War in Human Civilization (Oxford: Oxford University Press).

Godfrey-Smith, P. (2003). Theory and Reality: An Introduction to the Philosophy of Science (Chicago: University of Chicago Press).

Graham, Gordon (1983). Historical Explanation Reconsidered (Aberdeen: Aberdeen University Press). 
Hempel, Carl (1959). "The Function of General Laws in History" in P. Gardiner (ed.), Theories of History (Glencoe, IL: Free Press), pp. 344-55. Repr. in Hempel 1965.

Hempel, Carl (1965). Aspects of Scientific Explanation and Other Essays in the Philosophy of Science (New York: Free Press).

Hempel, Carl (1972). "Explanation in Science and History," in R. Colodny (ed.), Frontiers of Science and Philosophy (Pittsburgh, PA: University of Pittsburgh Press), pp. 7-33.

Hempel, Carl (2001a). "Explanation in Science and History," in J. Fetzer (ed.), The Philosophy of Carl G. Hempel (Oxford: Oxford University Press), pp. 276-96.

Hempel, Carl (2001b). "Reasons and Covering Laws in Historical Explanation," in J. Fetzer (ed.), The Philosophy of Carl G. Hempel (Oxford: Oxford University Press), pp. 297-310.

Hempel, Carl and Oppenheim, Paul (1953). "The Logic of Explanation," in H. Feigl and M. Brodbeck (eds.), Readings in the Philosophy of Science (New York: Appleton-Century-Crofts), pp. 319-52. Repr. in Hempel 1965.

Hume, David (1978). A Treatise on Human Nature (Oxford: Clarendon Press).

Lewens, Tim (2007). Darwin (London: Routledge).

Lipton, Peter (2004). "What Is the Good in Explanation?” in J. Cornwell (ed.), Explanations: Styles of Explanation in Science (Oxford: Oxford University Press), pp. 1-21.

Martin, Rex (1977). Historical Explanation: Re-enactment and Practical Inference (Ithaca, NY: Cornell University Press).

Smart, J. J. C. (1990). “Explanation: Opening Address,” in Dudley Knowles (ed.), Explanation and Its Limits (Cambridge: Cambridge University Press), pp. 1-19.

Tucker, Aviezer (2004). Our Knowledge of the Past: A Philosophy of Historiography (Cambridge: Cambridge University Press).

Turchin, Peter (2003). Historical Dynamics (Princeton, NJ: Princeton University Press).

Van Fraassen, Bas (1980). The Scientific Image (Oxford: Oxford University Press).

Velleman, D. (2003). "Narrative Explanation,” Philosophical Review, 112(1), pp. 1-26.

White, H. V. (1973). Metahistory (Baltimore, MD: Johns Hopkins University Press).

Wright, Georg Henrik von (1971). Explanation and Understanding (Ithaca, NY: Cornell University Press). 